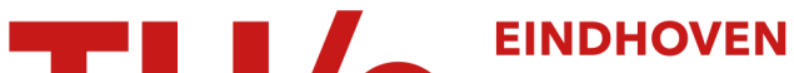 \\ UNIVERSITY OF \\ TECHNOLOGY
}

\section{$\mathrm{CO}$ adsorption on hydrogen saturated $\mathrm{Ru}(0001)$}

\section{Citation for published version (APA):}

Riedmüller, B., Ciobica, I. M., Papageorgopoulos, D. C., Frechard, F. G., Berenbak, B., Kleyn, A. W., \& Santen, van, R. A. (2001). CO adsorption on hydrogen saturated Ru(0001). Journal of Chemical Physics, 115(11), 52445251. https://doi.org/10.1063/1.1395625

DOI:

10.1063/1.1395625

Document status and date:

Published: 01/01/2001

\section{Document Version:}

Publisher's PDF, also known as Version of Record (includes final page, issue and volume numbers)

\section{Please check the document version of this publication:}

- A submitted manuscript is the version of the article upon submission and before peer-review. There can be important differences between the submitted version and the official published version of record. People interested in the research are advised to contact the author for the final version of the publication, or visit the $\mathrm{DOI}$ to the publisher's website.

- The final author version and the galley proof are versions of the publication after peer review.

- The final published version features the final layout of the paper including the volume, issue and page numbers.

Link to publication

\section{General rights}

Copyright and moral rights for the publications made accessible in the public portal are retained by the authors and/or other copyright owners and it is a condition of accessing publications that users recognise and abide by the legal requirements associated with these rights.

- Users may download and print one copy of any publication from the public portal for the purpose of private study or research.

- You may not further distribute the material or use it for any profit-making activity or commercial gain

- You may freely distribute the URL identifying the publication in the public portal.

If the publication is distributed under the terms of Article $25 f a$ of the Dutch Copyright Act, indicated by the "Taverne" license above, please follow below link for the End User Agreement:

www.tue.nl/taverne

Take down policy

If you believe that this document breaches copyright please contact us at:

openaccess@tue.nl

providing details and we will investigate your claim. 


\title{
CO adsorption on hydrogen saturated $\mathrm{Ru}(0001)$
}

\author{
B. Riedmüller \\ FOM-Institute for Atomic and Molecular Physics, Kruislaan 407, 1098 SJ Amsterdam, The Netherlands
}

I. M. Ciobîcă

FOM-Institute for Atomic and Molecular Physics, Kruislaan 407, 1098 SJ Amsterdam, The Netherlands, and Schuit Institute of Catalysis, Eindhoven University of Technology, P.O. Box 513, $5600 \mathrm{MB}$ Eindhoven, The Netherlands

D. C. Papageorgopoulos

FOM-Institute for Atomic and Molecular Physics, Kruislaan 407, 1098 SJ Amsterdam, The Netherlands

F. Frechard

Schuit Institute of Catalysis, Eindhoven University of Technology, P.O. Box 513, 5600 MB Eindhoven, The Netherlands

\section{B. Berenbak}

FOM-Institute for Atomic and Molecular Physics, Kruislaan 407, 1098 SJ Amsterdam, The Netherlands, and Department of Physical Chemistry, Faculty of Exact Sciences, Vrije Universiteit Amsterdam, The Netherlands and De Boelelaan 1083, 1081 HV Amsterdam, The Netherlands, and Leiden Institute of Chemistry, P.O. Box 9502, 2300 RA Leiden, The Netherlands
A. W. Kleyn ${ }^{\text {a) }}$
FOM-Institute for Atomic and Molecular Physics, Kruislaan 407, 1098 SJ Amsterdam, The Netherlands, and Leiden Institute of Chemistry, P.O. Box 9502, 2300 RA Leiden, The Netherlands

R. A. van Santen

Schuit Institute of Catalysis, Eindhoven University of Technology, P.O. Box 513, 5600 MB Eindhoven, The Netherlands

(Received 5 October 2000; accepted 28 June 2001)

\begin{abstract}
The interaction of $\mathrm{CO}$ with the $\mathrm{Ru}(0001)(1 \times 1) \mathrm{H}$ surface has been studied by density functional theory $(\mathrm{DFT})$ periodic calculations and molecular beam techniques. The hydrogen $(1 \times 1)$ phase induces an activation barrier for $\mathrm{CO}$ adsorption with a minimum barrier height of $25 \mathrm{~kJ} \mathrm{~mol}^{-1}$. The barrier originates from the initial repulsive interaction between the CO-4 $\sigma$ and the Ru- $d_{3 z^{2}-r^{2}}$ orbitals. Coadsorbed $\mathrm{H}$ also reduces the $\mathrm{CO}$ adsorption energy considerably and enhances the site preference of $\mathrm{CO}$. On a $\mathrm{Ru}(0001)(1 \times 1) \mathrm{H}$ surface, $\mathrm{CO}$ adsorbs exclusively on the atop position. (C) 2001 American Institute of Physics. [DOI: 10.1063/1.1395625]
\end{abstract}

\section{INTRODUCTION}

The coadsorption of hydrogen and carbon monoxide on the close-packed $\mathrm{Ru}(0001)$ surface is particularly interesting because of its relevance to the Fischer-Tropsch synthesis and the methanation reaction. ${ }^{1-3}$ While $\mathrm{CO}$ and $\mathrm{H}_{2}$ adsorption on the ruthenium surface has been studied quite extensively over the past decades, little information is available for the hydrogen carbon monoxide coadsorption system on $\mathrm{Ru}(0001)$.

The saturation fractional coverage of dissociatively chemisorbed molecular hydrogen is one adatom per $\mathrm{Ru}(0001)$ unit cell. ${ }^{4}$ While at low surface coverages $\mathrm{H}$ resides in the fcc-threefold hollow sites, at saturation coverage $\mathrm{H}$ was found to occupy a site of slightly reduced symmetry. This is presumably due to either a shift of the hydrogen adatom towards the bridge position or a reconstruction of the ruthenium surface. ${ }^{5}$ Recent DFT-GGA calculations revealed that the adsorption energy below 1 ML hardly varies with coverage. $\mathrm{H}$ can be adsorbed up to $\approx 1.5 \mathrm{ML}$ (Ref. 6) with a

${ }^{a)}$ Electronic mail: a.kleyn@chem.leidenuniv.nl small decrease in adsorption energy. Above 1.5 ML the adsorption energy becomes very small and tends to zero at 2 ML.

The $\mathrm{CO}$ on $\mathrm{Ru}(0001)$ adsorption system has been studied widely. ${ }^{7,8} \mathrm{CO}$ is known to adsorb nondissociatively ${ }^{7}$ in the upright position, with the $\mathrm{C}$ end facing the surface. ${ }^{9}$ The adsorption is nonactivated and a precursor model including two intrinsic and one extrinsic precursor has been proposed. ${ }^{10}$ The adsorption energy varies with coverage from 160 to $175 \mathrm{~kJ} \mathrm{~mol}^{-1}$ (Ref. 11) in the $0-0.33 \mathrm{ML}$ coverage regime. The preferred site is the atop site for coverages up to $\theta=0.33 .{ }^{8}$ Note that in this paper adsorption energies are presented with inverse sign. In this respect, a lower energy means a more weakly bound species and vice versa. CO adsorption and dissociation on transition metals has been investigated quite extensively on a theoretical basis by applying various computational methods. Delbecq et al. investigated $\mathrm{CO}$ and $\mathrm{NO}$ adsorption on $\mathrm{Pd}(100), \mathrm{Pd}(111)$, $\mathrm{Pd}_{3} \mathrm{Mn}(100)$, and $\mathrm{Pd}_{3} \mathrm{Mn}(111)$ using extended Hückel ${ }^{12}$ and DFT (Refs. 13, 14) methods. The bridge and the threefold hollow sites are preferred for $\mathrm{CO}$ adsorption on bare Pd sur- 
faces. On alloy surfaces, $\mathrm{CO}$ adsorption is generally weaker. LDA calculations were carried out by Eichler et al. ${ }^{15}$ to examine the $\mathrm{CO}$ adsorption behavior on a $\mathrm{Rh}(100)$ surface. The bridge position is the most stable adsorption site for $\mathrm{CO}$ at all coverages. The ratio between $\mathrm{CO}$ molecules adsorbed at the bridge and the atop sites is not constant with the coverage. The difference between the adsorption energies for the bridge and atop positions shows a minimum at halfcoverage. At high coverage $\mathrm{CO}$, forms a pseudohexagonal overlayer with $p(4 \sqrt{2} \times \sqrt{2})$ periodicity. Morikawa et al. reported DFT calculations on CO decomposition on $\mathrm{Ni}(111)$ and $\mathrm{Pt}(111)$, the LDA results are corrected with GGA. ${ }^{16}$ The Pt surface is found to be less active, in agreement with experimental results. In the transition state a very long $\mathrm{C}-\mathrm{O}$ bond $(2.0 \AA)$ is observed with the $\mathrm{C}$ atom being adsorbed in a threefold site, while the $\mathrm{O}$ atom is in a bridge site. Large scale DFT calculations are used by Hammer et al. to investigate the interaction of $\mathrm{CO}$ with stepped and reconstructed Pt surfaces. ${ }^{17}$ The adsorption energy on the steps is $70 \mathrm{~kJ} \mathrm{~mol}^{-1}$ higher than on the flat terraces. A systematic study of the adsorption of $\mathrm{CO}$ on the $\mathrm{Pt}(100), \operatorname{Pt}(110)$, and $\mathrm{Pt}(111)$ is presented by Curulla et al. using HF ab initio cluster models. ${ }^{18}$ The geometries and vibrational frequencies are invariant with the cluster size. However, the adsorption energies are very sensitive to the cluster size. The bonding interaction is dominated by the $\pi$-backdonation, although the $\sigma$-donation plays a significant role. A database of DFT GGA calculations of the chemisorption energies of $\mathrm{CO}$ over hexagonal compact surfaces of $\mathrm{Ni}, \mathrm{Cu}, \mathrm{Ru}, \mathrm{Pd}, \mathrm{Ag}, \mathrm{Pt}, \mathrm{Au}$, and $\mathrm{Cu}_{3} \mathrm{Pt}$ is provided by Hammer et al. ${ }^{19}$ The smallest adsorption energies are found for $\mathrm{Au}(111)$ and $\mathrm{Ag}(111)$, the highest one is obtained for $\mathrm{Ru}(0001)$.

$\mathrm{CO}$ coadsorption with atomic $\mathrm{O}$ on $\mathrm{Ru}(0001)$ has been studied by Stampfl et al. using DFT. ${ }^{20,21}$ The oxidation rate of $\mathrm{CO}$ is enhanced at high coverages of atomic $\mathrm{O}$ because of a weakening of the $\mathrm{O}-\mathrm{Ru}$ bonds. At low coverage both $\mathrm{CO}$ and atomic $\mathrm{O}$ are strongly bound and this inhibits $\mathrm{CO}_{2}$ formation. The coadsorption of $\mathrm{O}$ and $\mathrm{CO}$ leads to various stable situations. Atomic oxygen resides primarily in threefold hollow sides. At low oxygen coverages, $\mathrm{CO}$ induces a restructuring of the $\mathrm{O}$-overlayer to maintain its favorite atop position. Upon increasing the $\mathrm{O}$-coverage, this position is not accessible anymore and $\mathrm{CO}$ has to adsorb in the hcp site. Furthermore, when $\mathrm{CO}$ approaches the surface a barrier of $30 \mathrm{~kJ} \mathrm{~mol}^{-1}$ has to be overcome. The oxidation reaction occurs on a $(1 \times 1) \mathrm{O}$ phase and can proceed via two channels, namely the Eley-Rideal and the Langmuir-Hinshelwood mechanisms in which the latter one dominates. Wang et al. also reported a study of $\mathrm{CO}$ coadsorption with atomic $\mathrm{O}$ on $\mathrm{Ru}(0001)$ focusing on the tilting of $\mathrm{CO}^{22}$ The DFT calculations have been performed with a cluster model. The interaction between $\mathrm{CO}$ and $\mathrm{O}$ can be described as a field-induced chemistry; the charged atomic oxygen creates a local electrostatic field along the $\mathrm{CO}$ adsorption site which modifies the metal-carbon and the $\mathrm{C}-\mathrm{O}$ bonds, resulting in a tilt of the molecule.

The coadsorption of $\mathrm{H}$ and $\mathrm{CO}$ has been studied by Peebles et al. ${ }^{23}$ They showed experimentally that the CO sticking probability drops with increasing deuterium cover- age, meaning that deuterium acts as a site blocker for $\mathrm{CO}$ adsorption. There was no evidence for a chemical reaction between $\mathrm{H}$ and $\mathrm{CO}$ at $100 \mathrm{~K}$ and no additional thermal desorption states appear in the TDS. A strong repulsive interaction between the deuterium atoms and carbon monoxide was also found. Further evidences for this observation were provided by Mak et al. ${ }^{24}$ who determined the $\mathrm{H}$ diffusion coefficients as a function of preadsorbed $\mathrm{CO}$ coverage $\left(\theta_{\mathrm{CO}}\right.$ $=0-0.2 \mathrm{ML}$ ) at $T=260 \mathrm{~K}$ with LITD. They found a $\mathrm{H}$ exclusion radius which is in the order of the van der Waals radius of the $\mathrm{CO}$ molecule.

However, even on a fully deuterium saturated surface, considerable amounts of $\mathrm{CO}$, up to $20 \%$ of the $\mathrm{CO}$ saturation coverage, could be adsorbed. ${ }^{23}$ Since the D-CO interaction is repulsive in the mixed overlayer and deuterium blocks adsorption sites, an interesting question is, how a gas phase $\mathrm{CO}$ molecule adsorbs in the $\mathrm{H}$ overlayer.

In the current study, molecular beam experiments and DFT calculations have been carried out to provide a better insight into the dynamic process of coadsorption. Experiments and theoretical predictions agree that $\mathrm{CO}$ adsorption in a $\mathrm{H}$ saturated overlayer is an activated process.

\section{METHODS}

\section{A. Theoretical method and surface model}

The quantum chemical study was performed using the VASP (Refs. 25, 26) code which allows periodic DFT calculations with pseudopotentials and a plane wave basis set. The approach implemented in the program is based on a generalized gradient approximation with the Perdew-Wang 91 functional. ${ }^{27}$ The Methfessel and Paxton's smearing $\operatorname{method}^{28}(\sigma=0.2 \mathrm{eV})$ is applied to the electron distribution, it results that the free energy is the variational quantity and the energy is extrapolated for $\sigma=0.0$. The interactions between the ions and the electrons are described by ultrasoft pseudopotentials (US-PP) introduced by Vanderbilt ${ }^{29}$ and provided by Kresse and Hafner. ${ }^{30}$

We used 4 layers slab with 5 vacuum layers in between in a $2 \times 2$ supercell to describe the surface. Adsorption on both sides with an inversion center prevents the generation of dipole-dipole interactions between the supercells. The $k$-points sampling was generated following the MonkhorstPack procedure with a $5 \times 5 \times 1$ mesh. The cutoff energy for the plane waves basis set is $400.0 \mathrm{eV}$. The coordinates of all atoms were fully optimized. All the parameters (the $k$-points mesh, the number of metal and vacuum layers, etc.) were tested and carefully selected. ${ }^{31}$

\section{B. Experiments}

The experimental setup used in this study has been described in more detail elsewhere. ${ }^{32,33}$ Briefly, the system consists of a three-stage differentially pumped molecular beam line attached to an UHV chamber equipped with a low energy electron diffraction (LEED) system, an ion sputter gun, and a residual gas analyzer. The Ruthenium crystal used was cut and polished to within $0.1^{\circ}$ and cleaned by consecutive argon sputtering treatments. Residual carbon was removed by annealing the crystal in oxygen. The surface quality was 
TABLE I. The adsorption energies $E_{\text {ads }}\left(\right.$ in $\left.\mathrm{kJ} \mathrm{mol}^{-1}\right)$ of $\mathrm{CO}$ adsorbed on $\mathrm{Ru}(0001)$ and $\mathrm{H}$ saturated $\mathrm{Ru}(0001)$. Adsorption energies for various adsorption geometries and the corresponding bond lengths (in $\AA$ ) for the $\mathrm{Ru}-\mathrm{C}$ and the $\mathrm{C}-\mathrm{O}$ bonds are also listed.

\begin{tabular}{lcccccc}
\hline \hline \multicolumn{1}{c}{ System } & $\begin{array}{c}\text { CO atop } \\
\text { (no H) }\end{array}$ & $\begin{array}{c}\text { CO hcp } \\
\text { (no H) }\end{array}$ & $\begin{array}{c}\text { CO atop } \\
+4 \mathrm{H} \mathrm{fcc}\end{array}$ & $\begin{array}{c}\text { CO hcp } \\
+4 \mathrm{Hfcc}\end{array}$ & $\begin{array}{c}\text { CO atop } \\
+4 \text { H hcp }\end{array}$ & $\begin{array}{c}\text { CO fcc } \\
+4 \mathrm{H} \mathrm{hcp}\end{array}$ \\
\hline Energy $\left(\mathrm{kJ} \mathrm{mol}^{-1}\right)$ & -173.3 & -173.0 & -45.1 & +6.2 & -74.6 & -9.8 \\
$\mathrm{C}-\mathrm{O}(\AA)$ & 1.17 & 1.19 & 1.16 & 1.19 & 1.16 & 1.19 \\
$\mathrm{Ru}-\mathrm{C}(\AA)$ & 1.90 & 2.15 & 1.89 & 2.17 & 1.87 & 2.17 \\
\hline \hline
\end{tabular}

checked by LEED and by the Debye-Waller analysis of the thermal helium reflectivity which extrapolated to $I / I_{0}=1$ at $0 \mathrm{~K}$, where $I_{0}$ is the incident He-beam intensity indicating a perfectly flat surface. $\mathrm{H}$ overlayers were prepared by background dosing $2.5 \times 10^{-7}$ mbar hydrogen for $10 \mathrm{~min}$ at 100 $\mathrm{K}(150 \mathrm{~L})$.

The translational energy of the beam was varied by using different seeding mixtures of $\mathrm{CO}$ in helium and heating the alumina nozzle (300-1100 K). The translational energy of the beam was derived from the TOF distributions which were fitted to shifted Maxwell-Boltzmann distributions. Corrections for triggering time delay, flight time through the QMS and the finite slit width of the chopper have been taken into account. Sticking probabilities larger than 5\% were determined using the adsorption reflection technique developed by King and Wells (K\&W). ${ }^{34,35}$ Smaller sticking coefficients were determined from taking the initial slope of the $\mathrm{CO}$ uptake (measured by TPD) against beam exposure.

\section{RESULTS AND DISCUSSION}

\section{A. Calculations}

For a bare $\mathrm{Ru}(0001)$ surface the adsorption energies of $\mathrm{CO}$ atop ${ }^{36}$ is about $185 \mathrm{~kJ} \mathrm{~mol}^{-1}$ for $33.3 \%$ coverage and $173 \mathrm{~kJ} \mathrm{~mol}^{-1}$ for $25.0 \%$ coverage. The adsorption energies of $\mathrm{CO}$ in the hollow hep site (one Ru atom from the second layer under the threefold hollow site) is $173 \mathrm{~kJ} \mathrm{~mol}^{-1}$ for both coverages. The other sites (fcc and the bridge) present smaller adsorption energies $\left(165 \mathrm{~kJ} \mathrm{~mol}^{-1}\right.$ for fcc and $157 \mathrm{~kJ} \mathrm{~mol}^{-1}$ for bridge in $2 \times 2$ and $163 \mathrm{~kJ} \mathrm{~mol}^{-1}$ for $\sqrt{3}$ $\times \sqrt{3}$ ). Allowing the $\mathrm{CO}$ molecule to tilt will increase the adsorption energy by $6 \mathrm{~kJ} \mathrm{~mol}^{-1}$ for the atop and the bridge sites $\left(\theta_{\text {tilt }} \approx 3^{\circ}\right)$, while for the hcp and fcc sites no change is observed. The $\mathrm{O}$ end adsorption of $\mathrm{CO}$ is not possible in any site, the $\mathrm{CO}$ molecule being repelled from the surface. Those results are in good agreement with experimental results. ${ }^{37}$

The fully covered hydrogen $\mathrm{Ru}(0001)$ surface was simulated in a $2 \times 2$ supercell, with 4 layers slab, where $4 \mathrm{H}$ atoms on each surface were placed. At low coverage the $\mathrm{H}$ atoms prefer the fcc site (no Ru atom from the second layer under the threefold hollow site), but the difference per $\mathrm{H}$ atom between adsorption in a hcp or a fcc site is very small with $3.0 \mathrm{~kJ} \mathrm{~mol}^{-1}$ at $25 \%$ coverage ${ }^{31}$ and $4.5 \mathrm{~kJ} \mathrm{~mol}^{-1}$ at $100 \%$ coverage.

The incoming $\mathrm{CO}$, from the gas phase, can be adsorbed on 2 different sites for each of the two fully hydrogen covered $\mathrm{Ru}(0001)$ surfaces. Those four situations are displayed in Table I together with the adsorption energies. The adsorption energies of the $\mathrm{CO}$ in the nonoccupied threefold site are less stable compared to the top site. An important contribution to the difference between the adsorption energy of the $\mathrm{CO}$ atop on the two different hydrogenated $\mathrm{Ru}(0001)$ surfaces is their relative stability: the surface with $\mathrm{H}$ atoms adsorbed in fcc sites is $18 \mathrm{~kJ} \mathrm{~mol}^{-1}$ (per $4 \mathrm{H}$ atoms) more stable.

If $\mathrm{CO}$ is adsorbed atop, the three neighboring $\mathrm{H}$ atoms will slightly shift (see Fig. 1, top). For $\mathrm{H}$ adsorbed in the fcc (hcp) site, two Ru-H bonds of 1.83 (1.83) $\AA$ and one of 1.87 (1.86) $\AA$ are formed. One $\mathrm{H}$ will be not effected because of the symmetries, the respective values for the $\mathrm{Ru}-\mathrm{H}$ bond lengths are $1.89 \AA$ for $\mathrm{H}$ fcc and $1.88 \AA$ for $\mathrm{H}$ hcp.

In the case that $\mathrm{CO}$ is adsorbed in the threefold hollow sites, three $\mathrm{H}$ atoms will undergo a noticeable displacement
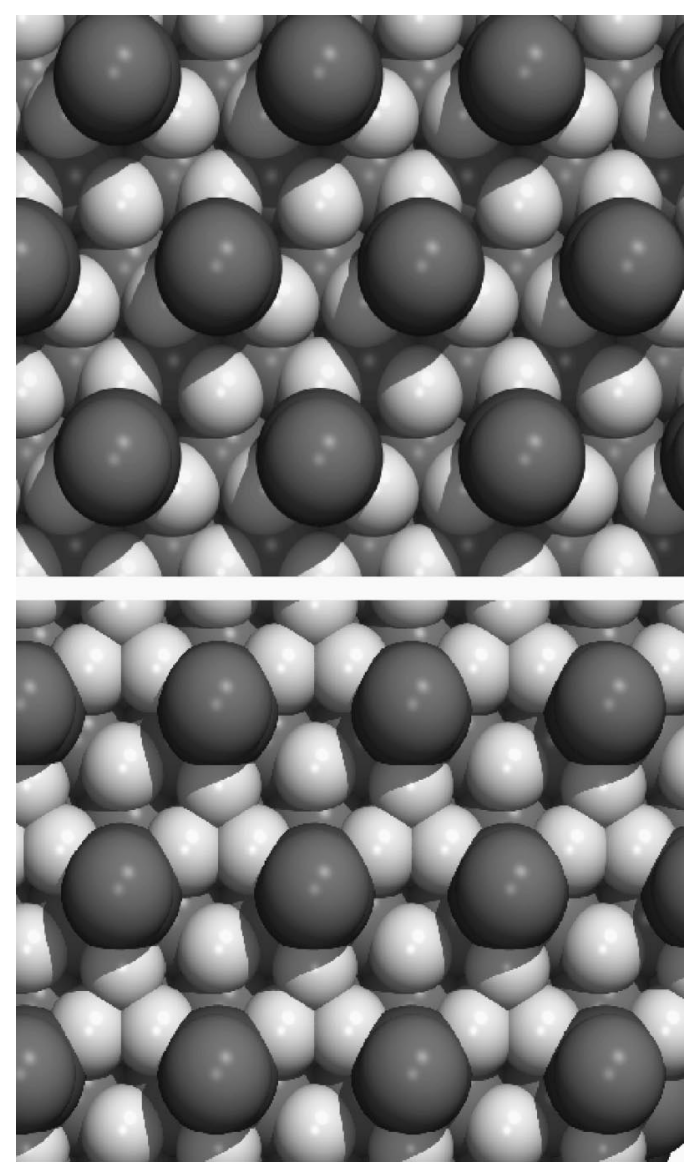

FIG. 1. The topology of $\mathrm{CO}$ adsorbed on a hydrogenated $\mathrm{Ru}(0001)$ surface. The top part shows $\mathrm{CO}$ molecules adsorbed at the atop sites (25\% coverage) together with $4 \mathrm{H}$ atoms adsorbed in fcc sites (100\% coverage). The bottom part shows the topology of CO molecules adsorbed in the hcp site $(25 \%$ coverage) together with $\mathrm{H}$ atoms adsorbed on fcc sites (100\% coverage). 
away from $\mathrm{CO}$ (see Fig. 1, bottom). So, for $\mathrm{CO}$ adsorbed hcp (fcc) and $4 \mathrm{H}$ adsorbed fcc (hcp) two $\mathrm{Ru}-\mathrm{H}$ bonds are $2.22 \AA$ $(2.16 \AA)$, one $1.63 \AA(1.65 \AA)$ for the three shifted $\mathrm{H}$ atoms and $1.89 \AA(1.88 \AA)$ for the other $\mathrm{H}$ atom. Table I shows the bond distances for $\mathrm{C}-\mathrm{O}$ and $\mathrm{C}-\mathrm{Ru}$ in those four cases together with the bond distances for $\mathrm{CO}$ adsorption on bare $\mathrm{Ru}$ surface.

In the case of $\mathrm{H}$ coadsorbed fcc, atop adsorption of $\mathrm{CO}$ drops the interaction energy considerably (see Table I) to $45.1 \mathrm{~kJ} \mathrm{~mol}^{-1}$. Adsorption of $\mathrm{CO}$ on the hcp site becomes weakly repulsive. When $\mathrm{H}$ is coadsorbed in the less favorable site hcp, the adsorption energy of CO atop decreases less with $74.6 \mathrm{~kJ} \mathrm{~mol}^{-1}$. However the total adsorption energy including the $4 \mathrm{H}$ atoms differs only by $11.5 \mathrm{~kJ} \mathrm{~mol}^{-1}$ with the first case. When $\mathrm{H}$ is coadsorbed in hcp sites, $\mathrm{CO}$ adsorbed in the fcc site becomes also weakly bond. This state is destabilized compared to the analogous first situation.

As we will see later, $\mathrm{H}$ and $\mathrm{CO}$ sharing a metal atom will have repulsive interactions which are reduced by the $\mathrm{H}$ atoms moving away from $\mathrm{CO}$. A reduced hindrance is obtained for the $\mathrm{CO}$ molecule adsorbed in the top site, the $\mathrm{H}$ atoms are pushed toward bridge sites, while for $\mathrm{CO}$ adsorbed in the hcp site the $\mathrm{H}$ atoms are displaced toward the less stable atop sites. (The adsorption energy for $\mathrm{H}$ atop is $9 \mathrm{~kJ} \mathrm{~mol}^{-1}$ while for the $\mathrm{H}$ bridge it is $41 \mathrm{~kJ} \mathrm{~mol}^{-1}{ }^{6}$ ) Also, when $\mathrm{CO}$ is in threefold sites the $\mathrm{H}$ atoms on the surface are more compressed (Fig. 1, top and bottom) as the $\mathrm{CO}-\mathrm{H}$ distance can only be increased at the cost of significant repulsive interaction between the $\mathrm{H}$ atoms.

In conclusion the atop sites are the preferred sites for $\mathrm{CO}$ adsorption on the hydrogenated $\mathrm{Ru}(0001)$ surface.

For the two most favorable cases on the hydrogen covered surface, we investigated the reaction path and the origin of the adsorption barrier. On the bare ruthenium surface $\mathrm{CO}$ adsorption is known to be nonactivated. ${ }^{38,39}$ Some points on the potential energy surface were chosen by fixing the distance between the carbon atom and the surface plane (practically the $z$ coordinate of the $\mathrm{C}$ atom was not allowed to change). The TS is refined by performing a quasi-Newtonian optimization of the geometry based on the forces and not on the energy. $\mathrm{CO}$ :

Two situations were considered during the adsorption of

(1) Adiabatic reaction, the $\mathrm{CO}$ motion is slow enough to allow the metal surface to fully relax;

(2) Nonadiabatic reaction, the $\mathrm{CO}$ motion is so fast that the metal atoms cannot relax, the positions of the surface metal atoms are frozen while the $\mathrm{H}$ atoms are free.

In all these calculations $\mathrm{CO}$ remains perpendicular with respect to the surface plane and above its adsorption site. For both approaches, a similar barrier around $24 \mathrm{~kJ} \mathrm{~mol}^{-1}$ is found (see Fig. 2). The major difference between the two different situations (e.g., the adiabatic and nonadiabatic cases) is that, in the case where the CO approaches slowly, the $\mathrm{Ru}$ atom underneath the $\mathrm{CO}$ molecule can move upward to initiate the bond. This vertical displacement of the $\mathrm{Ru}$ atom is about $0.4 \AA$ for $\mathrm{H}$ adsorbed fcc and $0.5 \AA$ for $\mathrm{H}$ atom adsorbed hcp in the minimum of the potential energy surface,

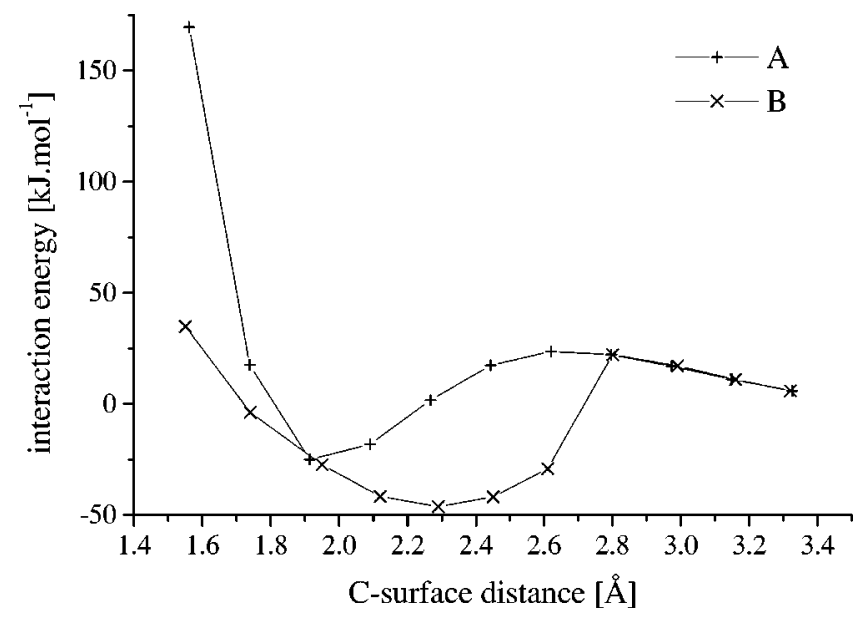

FIG. 2. The calculated potential energy surface for $\mathrm{CO}$ adsorption on a $\mathrm{H}$ covered $\mathrm{Ru}(0001)$ surface $(100 \%)$. (A) $\mathrm{CO}$ atop $+4 \mathrm{H}$ fcc without relaxation of the surface, (B) $\mathrm{CO}$ atop $+4 \mathrm{H}$ fcc with relaxation of the surface. The $y$ axis denotes the interaction energy in $\mathrm{kJ} \mathrm{mol}^{-1}$. The $x$ axis denotes the distance in $\AA$ from the $\mathrm{C}$ atom of the CO molecule to the surface (i.e., the plane is defined by the three $\mathrm{Ru}$ atoms which remain in position).

but the displacement is much larger near the transition state with $0.7 \AA$ for $\mathrm{H}$ adsorbed fcc and $0.8 \AA$ for $\mathrm{H}$ adsorbed hcp. If the metal atoms are frozen, the $\mathrm{H}$ atoms will be moved away from the $\mathrm{Ru}$ atom bound to $\mathrm{CO}$. Long $\mathrm{Ru}-\mathrm{H}$ distances are $2.15 \AA$ (if $\mathrm{H} \mathrm{fcc}$ ) or $2.18 \AA$ (if $\mathrm{H}$ hcp), short $\mathrm{Ru}-\mathrm{H}$ distances are $1.79 \AA$ (if $\mathrm{H} \mathrm{fcc}$ ) or $1.78 \AA$ (if $\mathrm{H} \mathrm{hcp}$ ), and the normal $\mathrm{Ru}-\mathrm{H}$ distances are $1.89 \AA$ (if $\mathrm{H} \mathrm{fcc}$ ) or $1.88 \AA$ (if $\mathrm{H}$ hcp).

The main difficulty to describe the adiabatic adsorption path (curve B, Fig. 2) is that on the left of the TS the Ru atom moves upward to bound to $\mathrm{CO}$ and downward with $\mathrm{CO}$ as the system goes to the minimum. Hence, the important change for the adsorption energy for a small variation of the $\mathrm{C}$-surface distance and the cusped curve. A better description of the the adiabatic path would need at least a two dimensions potential energy surface which would show a very curved path once the TS is reached.

For the $\mathrm{CO}$ atop $+4 \mathrm{H}$ fcc system the transition state has also been searched with the "nudged elastic band" method of Jónsson ${ }^{40}$ and the same barrier height was found.

Since CO is allowed to get the best geometry to adsorb, the calculated barrier should be the smallest possible. The influence of the $\mathrm{C}-\mathrm{O}$ bond orientation with respect to the surface normal, has been checked by tilting the $\mathrm{CO}$ molecule in the transition state. For each calculation, the $z$ coordinate of the $\mathrm{C}$ atom and the $x$ and $y$ coordinates of $\mathrm{O}$ are frozen once the molecule is tilted. The differences are rather small for angles between $0^{\circ}$ and $35^{\circ}$.

The projected DOS diagrams (Fig. 3) for the CO adsorption on the bare and hydrogenated $\mathrm{Ru}(0001)$ surfaces bring us to the following conclusions about the quantum chemical basis for activated adsorption and destabilization of $\mathrm{CO}$ by coadsorbed $\mathrm{H}$.

First, the $\sigma$ type interactions between the $\mathrm{CO} 4 \sigma$ and $5 \sigma$ with $\mathrm{Ru}$ on the clean surface are considered. The downwards shift of $5 \sigma$ and the broadening of the metal $d$-band agree with the conventional picture of a bonding occupied $5 \sigma$ type 

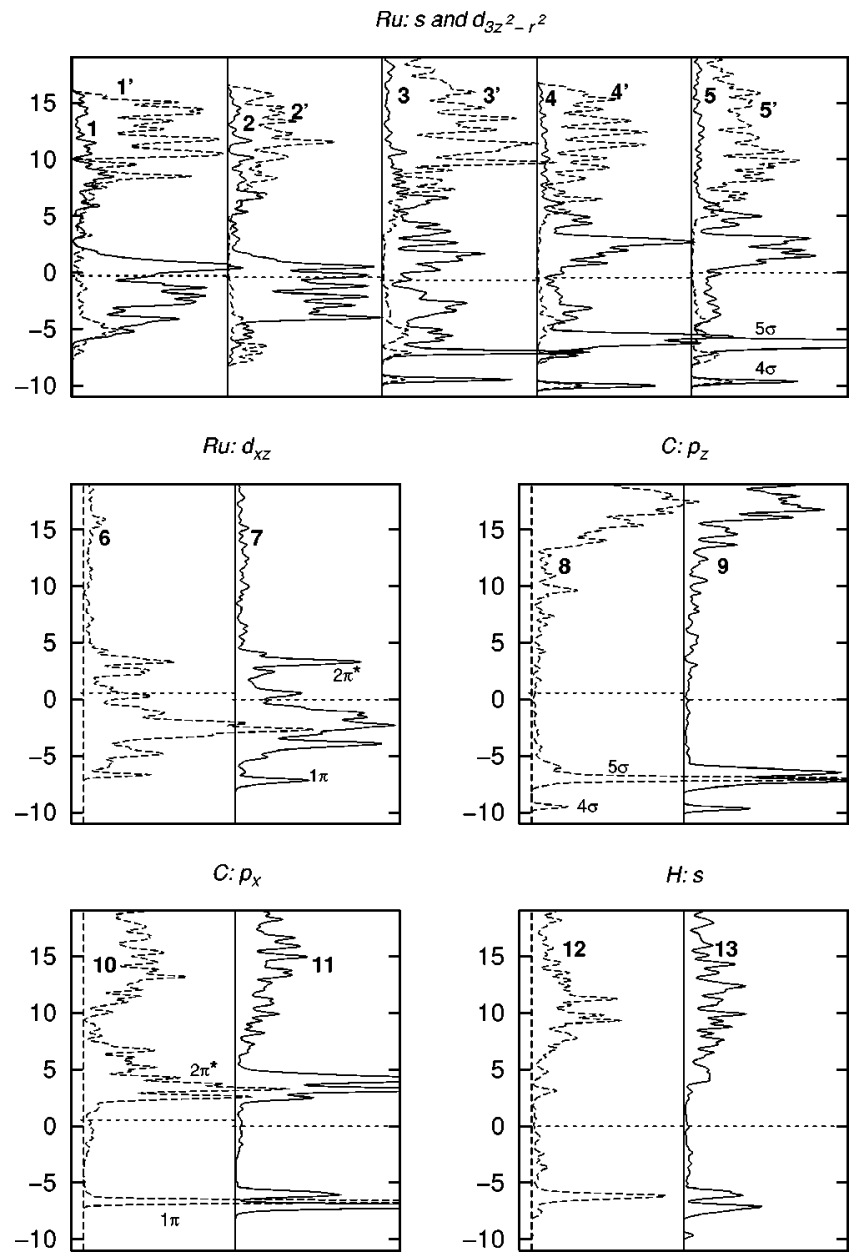

FIG. 3. (Upper panel) The DOS diagrams of the Ru $s$ and Ru $d_{3 z^{2}-r^{2}}$ atomic orbitals. Solid lines denote DOS of Ru $d_{3 z^{2}-r^{2}}$ orbitals (labeled \#), dashed ones DOS of the $\mathrm{Ru}_{s}$ orbitals (labeled with \#'). The following situations have been calculated: $\left(1,1^{\prime}\right)$ the bare surface: $\left(2,2^{\prime}\right)$ surface with $4 \mathrm{H}$ atoms (fcc, 100\%); (3, $\left.3^{\prime}\right) \mathrm{Ru}(0001)(2 \times 2) \mathrm{CO} ;\left(4,4^{\prime}\right)$ coadsorption of $4 \mathrm{H}$ and $\mathrm{CO}$ on a "frozen" surface; $\left(5,5^{\prime}\right)$ same situation as $\left(4,4^{\prime}\right)$ but the surface is allowed to relax. (Middle panels) The DOS diagrams for Ru- $d_{x z}$ (left panel) and C- $p_{z}$ (right panel) atomic orbitals. Dashed lines denote calculations for $\mathrm{CO}$ adsorbed on atop sites; solid ones denote DOS diagrams after $\mathrm{H}$ was added to all fcc sites available. (6) DOS of Ru- $d_{x z}$ orbital of the Ru-atom to which CO binds, (7) same orbital but with all fcc sites occupied by $\mathrm{H}$, (8) DOS of C- $p_{z}$ orbital, (9) after addition of $\mathrm{H}$ (fcc). (Lower panels) The DOS diagrams of the C- $p_{x}$ (left panel) and $\mathrm{H}-s$ (right panel) atomic orbitals. (10) DOS of C- $p_{x}$ orbital for CO adsorbed atop, (11) same orbital but with $\mathrm{H}$ coadsorbed in all fcc sites available, (12) DOS of $\mathrm{H}-s$ orbital of the $\mathrm{H}$ atom perfectly situated in a fcc site (13) DOS of $\mathrm{H}-s$ orbital of the $\mathrm{H}$ atoms which shifted towards the bridge sites due to the lateral repulsion. The $y$ axis denotes the energy in eV. The $x$ axis is in arbitrary units. The Fermi level was set to $0.0 \mathrm{eV}$ for the $\mathrm{CO}+4 \mathrm{H}$ fcc systems. For the other systems the lowest energy level was adjusted to the corresponding level of the $\mathrm{CO}+4 \mathrm{H}$ fcc system.

surface orbital and partially occupied antibonding $5 d$ type orbitals (see Fig. 3, panels 3 and 6).

The $\pi$ type interactions for the CO $1 \pi$ and $2 \pi^{*}$ with Ru on the clean surface are significant (see Fig. 3, panels 6 and $10)$. The $d$-band broadening indicates a small bonding component under the Fermi level $\left(\epsilon_{F}\right)$. The increased distance between the maxima of the $2 \pi^{*}$ and $1 \pi$ densities, compared to a free $\mathrm{CO}$ molecule, agrees with the antibonding nature of the $2 \pi^{*}$ interaction above $\epsilon_{F}$. The adsorption of $\mathrm{CO}$ on a bare $\mathrm{Ru}(0001)$ surface is not activated as two opposite phenomena occur simultaneously: the $5 \sigma-\mathrm{Ru}-d_{3 z^{2}-r^{2}}$ interaction is close to a 4 electrons interaction which should give at the beginning two filled levels, bonding and antibonding, resulting in a repulsion. Only when the interaction is strong enough to push the antibonding level above $\epsilon_{F}$, the system is stabilized. At the same time, the CO-5 $\sigma-\mathrm{Ru}-s$ interaction is similar to a two electrons interaction (Ru- $s$ almost empty) which is bonding along the whole adsorption path and compensates the barrier arising from the $5 \sigma-\mathrm{Ru}-d_{3 z^{2}-r^{2}}$ antibonding component. The Ru- $p_{z}$ behaves like the Ru- $s$ but its influence is smaller.

In the presence of only adsorbed hydrogen the metal $d_{3 z^{2}-r^{2}}$ orbital band is more narrow. Indeed the bottom of the $d_{3 z^{2}-r^{2}}$ band is bonding for the Ru atoms and mixed with the $s$ band. Once $\mathrm{H}$ is adsorbed the $\mathrm{s}$ band interacts manly with the $\mathrm{H}$ atoms (Fig. 3, panel 2, 12, the PDOS 12 is similar to the PDOS for $\mathrm{H}$ atoms adsorbed without $\mathrm{CO}$, the only noticeable difference is the absence of the tiny peak around $-7.5 \mathrm{eV})$. The $s$ band is essentially involved in the bond with $\mathrm{H}$ and stabilized while the $d_{3 z^{2}-r^{2}}$ band is destabilized and narrowed. The other components of the $d$ band (not shown) are directly involved in the $\mathrm{Ru}-\mathrm{H}$ bond and consequently get an extra peak at the maximum of the H PDOS.

With $\mathrm{H}$ present on the $\mathrm{Ru}(0001)$ surface for adsorbed $\mathrm{CO}$, a small effect is seen on the $4 \sigma$ while it is more important for the $5 \sigma$ interaction (Fig. 3, panels 8 and 9). One has to remember that $\mathrm{CO}$ attracts the $\mathrm{Ru}$ atom which moves upwards the surface. This is a direct consequence of the $\mathrm{Ru}-\mathrm{Ru}$ bonds weakening from both $\mathrm{CO}$ and $\mathrm{H}$ binding. With $\mathrm{H}$ and $\mathrm{CO}$ coadsorbed, the middle of the $d_{3 z^{2}-r^{2}}$ is significantly depleted, compared to only $\mathrm{H}$ or $\mathrm{CO}$ adsorbed (Fig. 3, panels 2, 3 , and 4), the $d_{3 z^{2}-r^{2}}$ band is either part of bonding levels with $\mathrm{H}$ and $\mathrm{CO}$ or the related antibonding levels above $\epsilon_{F}$. The effects of the coadsorption are less pronounced for the other components of the $d$ band (Fig. 3, panels 6) as the interactions of the $\mathrm{CO} \pi$ orbitals are weaker.

A very small change is seen for the interaction with the CO $2 \pi^{*}$ orbitals, but a larger difference happens on the interaction with the $1 \pi$ once $\mathrm{H}$ is co-adsorbed. The $1 \pi$ projected orbital has a clear splitting (Fig. 3, panels 10 and 11) due to a direct interaction with the H-s levels. This interaction is bonding as the other $\mathrm{H}$ atom (not bound to $\mathrm{Ru}-\mathrm{CO}$ ) has only the upper component (Fig. 3, panels 11 and 12) and direct as the $d$ band is not involved (Fig. 3, panels 4 and 6). The $5 \sigma$ is also split but because of the coupling of the $5 \sigma$ and $1 \pi$ orbitals via the $\mathrm{Ru}-s-\mathrm{H}-s$ levels.

In summary two points are of importance:

(1) $\mathrm{CO}$ adsorbs nonactivated on the bare $\mathrm{Ru}(0001)$. A barrier appears if $\mathrm{H}$ is present on the surface. This is the consequence of the competing $\mathrm{Ru}-s-\mathrm{H}$ and $\mathrm{Ru}-s-\mathrm{CO}$ bonds. The interaction Ru-s with CO-5 $\sigma$ is always bonding. If $\mathrm{H}$ is present on the surface this interaction decreases and cannot compensate for the repulsions arising from the 4 electron type interaction of CO- $4 \sigma$ with doubly occupied $\mathrm{Ru}-d_{3 z^{2}-r^{2}}$. The barrier is not related to a direct interaction with the $\mathrm{H}$ atoms, the PDOS for the TS (not shown) do not depict any splitting for the $\mathrm{H}$ levels. At the TS for 


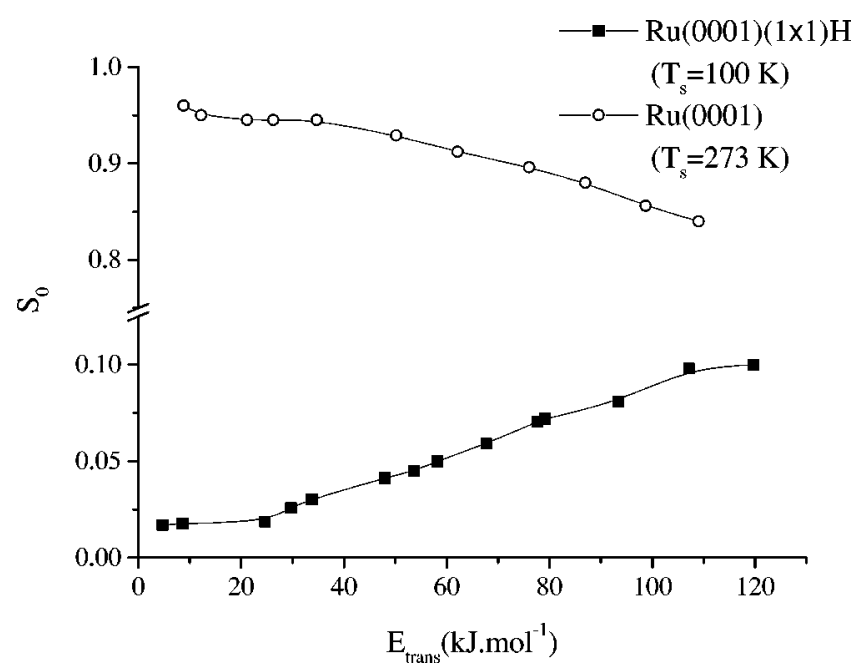

FIG. 4. The initial sticking coefficient $S_{0}$ of $\mathrm{CO}$ on clean and $\mathrm{H}$ saturated $\mathrm{Ru}(0001)$ at normal incident angle as a function of translational energy. The measurements were performed at $T_{s}=273 \mathrm{~K}$ for the clean and $T_{s}=100 \mathrm{~K}$ for the $\mathrm{H}$ covered surface, respectively.

$\mathrm{CO}$, only the $5 \sigma$ is significantly modified compared to the gas phase, the PDOS shows two peaks: the CO- $5 \sigma-\mathrm{Ru}-d_{3 z^{2}-r^{2}}$ peak slightly stabilized by around 1 $\mathrm{eV}$ and $2 \mathrm{eV}$ below a peak which is a mix of the $\mathrm{CO}-5 \sigma$, $\mathrm{H}-s$, and the other Ru- $d$.

(2) The adsorption energy for $\mathrm{CO}$ adsorption decreases when $\mathrm{H}$ is coadsorbed. This can be understood in terms of bond order conservation. The coordination number of $\mathrm{Ru}$ has increased. The $\mathrm{Ru}$ atom relaxes upwards because of the $\mathrm{Ru}-\mathrm{Ru}$ bonds weakening induced by the bonds formed with the $\mathrm{H}$ atoms and the $\mathrm{CO}$ molecule. For the frozen surface, the weakening of the $\mathrm{Ru}-\mathrm{H}$ bonds illustrates the competition between $\mathrm{CO}$ and $\mathrm{H}$ for bonding via the $\mathrm{Ru}-s$ orbital. The direct interaction between $\mathrm{CO}$ and $\mathrm{H}$ seems not repulsive as the common levels are stabilized.

\section{B. Experiments}

The dependency of the initial sticking probability, $S_{0}$, on incident translational energy for the clean and $\mathrm{H}$ covered surface is given in Fig. 4. Both measurements were taken at normal incidence angle, and at a surface temperature of 273 $\mathrm{K}$ for the clean and $100 \mathrm{~K}$ for the $\mathrm{H}$ covered surface. The dynamics of adsorption on the clean surface are described in more detail elsewhere. ${ }^{39}$ In the low energy regime between 0.08 and $30 \mathrm{~kJ} \mathrm{~mol}^{-1}$, the sticking coefficient on the clean surface remains constant at approximately 0.95 , and extrapolates to unity for zero incident energy. This is entirely consistent with a nonactivated process in the presence of a deep chemisorption well and has also been observed for $\mathrm{CO}$ on $\mathrm{Pt}(111),{ }^{41} \operatorname{Ir}(110),{ }^{42}$ and $\mathrm{Ni}(111) .{ }^{43}$ Upon increasing the incident energy, $S_{0}$ decreases gradually with incident energy to 0.82 at $100 \mathrm{~kJ} \mathrm{~mol}^{-1}$. The minor changes in sticking probability in the high energy regime is a consequence of the deep chemisorption well, determined to be around $170 \mathrm{~kJ} \mathrm{~mol}^{-1}$, depending on the conditions as discussed in the preceding section, where steric effects and impact sites

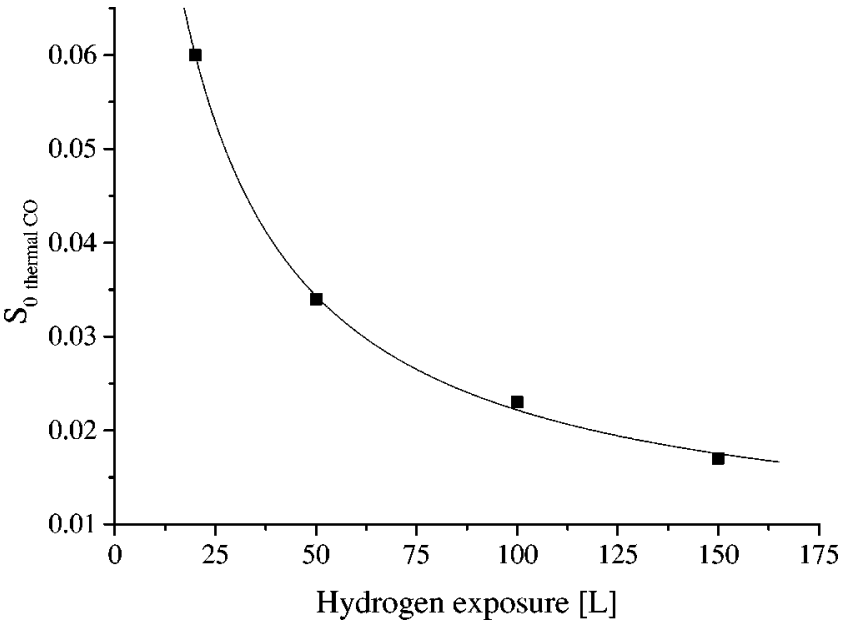

FIG. 5. The initial sticking coefficient, $S_{0}$, of thermal $\mathrm{CO}$ on a $\mathrm{Ru}(0001)$ $\times(1 \times 1) \mathrm{H}$ surface at $T_{s}=100 \mathrm{~K}$ plotted as a function of hydrogen exposure.

do not play a significant role. The results for $S_{0}$ on the clean surface are in qualitative agreement with those presented by Kneitz et al. ${ }^{44}$

Covering the surface with $\mathrm{H}(150 \mathrm{~L})$ at $100 \mathrm{~K}$ leads to a completely different scenario. For low incident energies $\left(\leqslant 24 \mathrm{~kJ} \mathrm{~mol}^{-1}\right)$ the sticking coefficient remains at a constant value below 0.02 . The surface is almost completely passivated for $\mathrm{CO}$ adsorption as is evident from the calculations. Similar results have been obtained by Peebles et al., ${ }^{23}$ who studied the relative initial sticking coefficient for thermal CO as a function of deuterium coverage. Their relative sticking coefficient decreases linearly with increasing deuterium coverage, and agrees qualitatively well with our results at the $\mathrm{H}$ saturation limit. At incident energies between $24 \mathrm{~kJ} \mathrm{~mol}^{-1}$ and $100 \mathrm{~kJ} \mathrm{~mol}^{-1}, S_{0}$ scales linearly with translational energy. Above $100 \mathrm{~kJ} \mathrm{~mol}^{-1}, S_{0}$ approaches a constant value of 0.1 . The tendency of the sticking probability curve clearly shows that an activated adsorption process is involved. The CO molecule has to overcome a barrier in order to chemisorb. Similar observations have also been made for NO on the $\mathrm{H}$ covered $\mathrm{Ru}(0001)$ (Ref. 45) surface.

In the low energy regime, however, the sticking coefficient does not drop to zero but stays constant at a value below 0.02 . This clearly indicates an additional nonactivated process which can be attributed to sticking at defect sites in the $\mathrm{H}$ overlayer. Evidence for this assertion is given in Fig. 5.

In order to determine the quality of the $\mathrm{H}$ overlayer we have measured the initial sticking probability of a thermal $\mathrm{CO}$ beam as a function of hydrogen exposure. The $\mathrm{CO}$ sticking coefficient decreases from 0.06 to 0.017 when increasing the hydrogen exposure from $20 \mathrm{~L}$ to $150 \mathrm{~L}$ at a surface temperature of $100 \mathrm{~K}$. The solid line is to guide the eye. The measurement clearly shows that there is a relation between reactivity and the completeness of the adsorbed overlayer. The differences between the integrated areas under the $\mathrm{H}$ desorption peaks are very small, especially for exposure above $50 \mathrm{~L}$, and within the detection limit of our experimental setup $(\approx 5 \%$ of a ML). The CO sticking curve versus hydrogen exposure clearly shows that the initial sticking probability has not converged yet. Unfortunately, further in- 
crease in the hydrogen exposure leads to background adsorption of $\mathrm{CO}$ from the residual background gas in the chamber. Therefore, all values of $S_{0}$ for $\mathrm{CO}$ on the $\mathrm{Ru}(0001)(1$ $\times 1) \mathrm{H}$ surface presented here, are with respect to hydrogen exposures of $150 \mathrm{~L}$. Note that thermal fluctuations in the $\mathrm{H}$ overlayer could also play a role. Unfortunately, with the experimental tools available, it is not possible to characterize these sites more precisely.

With this in mind, we can estimate the onset of the activated reaction channel by subtracting the defect induced offset, and fitting a line through the linear regime of the sticking curve (see Fig. 4). From the intersection with the $x$-axis, we obtain a value for the minimum barrier height in the order of $23 \pm 3 \mathrm{~kJ} \mathrm{~mol}^{-1}$, which is in good agreement with the calculations (see also Fig. 2). As the majority of the unity cell is passivated, the maximum sticking coefficient expected should be low. Due to the repulsive O-end interaction, a considerable amount of molecules will be reflected. Approximately $50 \%$ of the molecules should impinge with an orientation where the $\mathrm{C}$-end is closer to the surface than the O-end.

Surprisingly, the activation barrier appears to be very broad, with a mean barrier height of $65 \mathrm{~kJ} \mathrm{~mol}^{-1}$ and a width of $20 \mathrm{~kJ} \mathrm{~mol}^{-1}$, which indicates a broad distribution of barrier heights over the unit cell and possibly also over the different molecular orientations. This result suggests that the minimum energy entrance channel appears to be very narrow, and additional energy is needed if the molecule is slightly laterally displaced with respect to the atop position. This could also imply, that at higher translational energies the precise impacts positions become less relevant and that sites other than the atop position might also lead to adsorption. The energy dependence of the sticking coefficient has the typical characteristics of a direct channel. Because of its relatively broad width, it resembles the direct dissociative reaction channel of molecules. In addition, the absence of an enhancement in the sticking coefficient for very low incident energies suggests that a trapping mediated channel is improbable, or not relevant, at the experimental temperature.

\section{CONCLUSION}

Contrary to the adsorption of $\mathrm{CO}$ on a bare $\mathrm{Ru}(0001)$ surface, $\mathrm{CO}$ adsorption on $\mathrm{H}$ covered $\mathrm{Ru}(0001)$ surface is an activated process, with the lowest barrier being $25 \mathrm{~kJ} \mathrm{~mol}^{-1}$ as found by DFT. This value was experimentally verified. Moreover, experiments revealed an additional nonactivated reaction channel, which is due to $\mathrm{CO}$ adsorption at defects and possibly due to fluctuation of $\mathrm{H}$-atoms within the $\mathrm{H}$ overlayer. At high $\mathrm{H}$ coverages (1 $\mathrm{H}$ per $1 \mathrm{Ru}), \mathrm{CO}$ adsorbs preferentially atop because this geometry allows a maximum $\mathrm{CO}-\mathrm{H}$ distance which is advantageous with respect to the $\mathrm{CO}-\mathrm{H}$ repulsion. When $\mathrm{CO}$ is adsorbed in a hollow site, its $\sigma$ levels interact with the same Ru levels as $\mathrm{H}$ : the in-phase combination of $d$ and $s$ orbitals which corresponds to the bottom (bonding between $\mathrm{Ru}$ ) of the $d-s$ band. With $\mathrm{CO}$ atop, the competition is reduced to the $\mathrm{Ru} s$ band. Also, when $\mathrm{CO}$ is hollow, the neighboring hydrogens tend to move to atop sites, as two of their three bonds are weakened, while with $\mathrm{CO}$ atop only one $\mathrm{Ru}-\mathrm{H}$ bond is reduced with the $\mathrm{H}$ atoms moving to an in-between hollow-bridge site.

Differences in the interaction of $\mathrm{CO}$ with the bare and hydrogenated $\mathrm{Ru}(0001)$ surface are basically due to changes in the interaction between $4 \sigma, 5 \sigma$ molecular orbitals of $\mathrm{CO}$ and the $d_{3 z^{2}-r^{2}}, s$, and $p_{z}$ orbitals of the $\mathrm{Ru}$ atom. If $\mathrm{H}$ is present on the surface, the bond between $5 \sigma-\mathrm{CO}$ and the $s$ orbital of $\mathrm{Ru}$ is weakened and the $d_{3 z^{2}-r^{2}}-4 \sigma$ repulsion induces a barrier for $\mathrm{CO}$ adsorption. As $\mathrm{CO}$ and $\mathrm{H}$ interact with the lower levels of the $d-s$ band, the Ru atom dramatically moves outwards by $0.4 \AA$, reflecting the strong weakening of the $\mathrm{Ru}-\mathrm{Ru}$ surface bonds. The reaction coordinate of $\mathrm{CO}$ adsorption on a hydrogenated $\mathrm{Ru}(0001)$ surface is dominated by the vertical motion of the metal atom and the need to minimize the $\mathrm{CO}-\mathrm{H}$ repulsions. This leads to a strongly localized interaction. There is an excellent agreement between theory and experiment concerning the supporting data for the molecular adsorption of $\mathrm{CO}$ on a hydrogenated $\mathrm{Ru}(0001)$ surface.

\section{ACKNOWLEDGMENTS}

This work is part of the research program of the "Stichting voor Fundamenteel Onderzoek der Materie (FOM)," which is financially supported by the "Nederlandse organisatie voor Wetenschappelijk Onderzoek (NWO)." This work has been accomplished under the auspices of NIOK, the Netherlands Institute for Catalysis Research, Lab Report No. UL-00-2-06. The calculation have been partially performed with NCF support (SC183). The authors thank Professor Dr. Hafner for the VASP code.

${ }^{1}$ H. N. Storch, N. Golumbic, and R. B. Anderson, The Fischer-Tropsch and Related Synthesis (Wiley, New York, 1951).

${ }^{2}$ M. A. Vannice, J. Catal. 50, 228 (1977).

${ }^{3}$ P. Winslow and A. T. Bell, J. Catal. 94, 385 (1985).

${ }^{4}$ Y. K. Sun and W. H. Weinberg, Surf. Sci. 214, L246 (1989).

${ }^{5}$ H. Shi and K. Jacobi, Surf. Sci. 313, 289 (1994).

${ }^{6}$ I. M. Ciobîcă, F. Frechard, R. A. van Santen, and A. W. Kleyn (unpublished).

${ }^{7}$ J. C. Fuggle, T. E. Madey, M. Steinkilberg, and D. Menzel, Surf. Sci. 52, 521 (1975).

${ }^{8}$ H. Pfnür, D. Menzel, F. M. Hoffmann, A. Ortega, and A. M. Bradshaw, Surf. Sci. 93, 431 (1980).

${ }^{9}$ J. C. Fuggle, T. E. Madey, M. Steinkilberg, and D. Menzel, Chem. Phys. 11, 307 (1975).

${ }^{10}$ H. Pfnür and D. Menzel, J. Chem. Phys. 79, 2400 (1983)

${ }^{11}$ H. Pfnür and D. Menzel, J. Chem. Phys. 79, 4613 (1983).

${ }^{12}$ F. Delbecq, B. Moraweck, and L. Vérité, Surf. Sci. 396, 156 (1998).

${ }^{13}$ F. Delbecq and P. Sautet, Chem. Phys. Lett. 302, 91 (1999).

${ }^{14}$ F. Delbecq and P. Sautet, Phys. Rev. B 59, 5142 (1999).

${ }^{15}$ A. Eichler and J. Hafner, J. Chem. Phys. 109, 5585 (1998).

${ }^{16}$ Y. Morikawa, J. J. Mortensen, B. Hammer, and J. K. Nørskov, Surf. Sci. 386, 67 (1997).

${ }^{17}$ B. Hammer, O. H. Nielsen, and J. K. Nørskov, Catal. Lett. 46, 31 (1997).

${ }^{18}$ D. Curulla, A. Clotet, and J. M. Ricart, J. Phys. Chem. B 103, 5246 (1999)

${ }^{19}$ B. Hammer, Y. Morikawa, and J. K. Nørskov, Phys. Rev. Lett. 76, 2141 (1996).

${ }^{20}$ C. Stampfl and M. Scheffler, Phys. Rev. Lett. 78, 1500 (1997).

${ }^{21}$ C. Stampfl and M. Scheffler, Surf. Sci. 433-435, 119 (1999).

${ }^{22}$ R. L. C Wang, H. J. Kreuzer, and D. Menzel, Z. Phys. Chem. (Munich) 202, 205 (1997).

${ }^{23}$ D. E. Peebles, J. A. Schreifels, and J. M. White, Surf. Sci. 116, 117 (1982).

${ }^{24}$ C. H. Mak, A. A. Deckert, and S. M. George, J. Chem. Phys. 8, 5242 (1989)

${ }^{25}$ G. Kresse and J. Furthmüller, Comput. Mater. Sci. 6, 15 (1996) 
${ }^{26}$ G. Kresse and J. Furthmüller, Phys. Rev. B 54, 11169 (1996).

${ }^{27}$ J. P. Perdew, Electronic Structure of Solids '91 (Akademie, Berlin, 1991).

${ }^{28}$ M. Methfessel and A. T. Paxton, Phys. Rev. B 40, 3616 (1989).

${ }^{29}$ D. Vanderbilt, Phys. Rev. B 41, 7892 (1990).

${ }^{30}$ G. Kresse and J. Hafner, J. Phys.: Condens. Matter 6, 8245 (1994).

${ }^{31}$ I. M. Ciobîcă, F. Frechard, R. A. van Santen, A. W. Kleyn, and J. Hafner, Chem. Phys. Lett. 311, 185 (1999).

${ }^{32}$ A. Raukema, R. J. Dirksen, and A. W. Kleyn, J. Chem. Phys. 103, 6217 (1995).

${ }^{33}$ A. Raukema, A. P. de Jongh, H. P. Alberda, R. Boddenberg, E. de Haas, A. W. Kleyn, H. Neerings, R. Schaafsma, and H. Veerman, Meas. Sci. Technol. 8, 253 (1997).

${ }^{34}$ D. A. King and M. G. Wells, Surf. Sci. 29, 454 (1972).

${ }^{35}$ D. A. King and M. G. Wells, Proc. R. Soc., London, Ser. A 339, 245 (1974).
${ }^{36}$ I. M. Ciobîcă, F. Frechard, R. A. van Santen, and A. W. Kleyn (unpublished).

${ }^{37}$ H. Pfnür, P. Feulner, and D. Menzel, J. Chem. Phys. 79, 4613 (1983).

${ }^{38}$ H. Pfnür and D. Menzel, J. Chem. Phys. 79, 2400 (1983).

${ }^{39}$ B. Riedmüller, I. M. Ciobîcă, D. C. Papageorgopoulos, B. Berenbak, R. A. van Santen, and A. W. Kleyn, Surf. Sci. 465, 347 (2000).

${ }^{40}$ H. Jónsson, G. Mills, and W. Jacobsen, Enrico Fermi Summer School (Lenci '97) Proceedings, 1997.

${ }^{41}$ J. Harris and A. C. Luntz, J. Chem. Phys. 91, 6421 (1989).

${ }^{42}$ H. P. Steinrück and R. J. Madix, Surf. Sci. 185, 36 (1987).

${ }^{43}$ S. L. Tang, J. D. Beckerle, M. B. Lee, and S. T. Ceyer, J. Chem. Phys. 84, 6488 (1986).

${ }^{44}$ S. Kneitz, J. Gemeinhardt, H. Koschel, G. Held, and H.-P. Steinrück, Surf. Sci. 433-435, 27 (1999)

${ }^{45}$ D. A. Butler, B. Berenbak, S. Stolte, and A. W. Kleyn, Phys. Rev. Lett. 78, 4653 (1997) 